\section{Freezing fibrosis at the source}

\section{By Lev Osherovich, Senior Writer}

Hyperactive skin cells cause fibrosis, but targets to prevent their pathogenic activation have been hard to pin down, thus making it difficult to intervene early in disease. Now, a European team has mapped out a pathway involving serotonin released by activated platelets that drives early steps in scleroderma, a form of dermal fibrosis. ${ }^{1}$

The findings could open up fibrotic disease as a therapeutic category for terguride, a serotonin receptor antagonist that Pfizer Inc. in-licensed from Ergonex Pharma GmbH last year. The platelet connection also could build the case for Amira Pharmaceuticals Inc.'s strategy of targeting receptors for plateletderived inflammatory mediators to treat fibrotic diseases.

Fibrosis involves scarring and hardening of

$$
\begin{aligned}
& \text { "Several compounds } \\
& \text { already in clinical use that } \\
& \text { target 5- } \mathrm{HT}_{2 \mathrm{~B}} \text { are known to } \\
& \text { be well tolerated." } \\
& \text {-Jörg Distler, } \\
& \text { University of Erlangen-Nuremberg }
\end{aligned}
$$

Indeed, small interfering RNA knockdown of 5- $\mathrm{HT}_{2 \mathrm{~B}}$ decreased serotonin-induced expression of connective tissue genes in cultured fibroblasts compared with that seen using mock siRNA controls.

Finally, the team tested the effect of pharmacological inhibition of $5-\mathrm{HT}_{2 \mathrm{~B}}$ in two mouse models of fibrosis. Both an experimental compound selective for $5-\mathrm{HT}_{2 \mathrm{~B}}$ and terguride, which inhibits $5-\mathrm{HT}_{2 \mathrm{~B}}$ and another closely related receptor, prevented fibrosis compared with vehicle.

Results were reported in The Journal of Experimental Medicine.

Distler's team also performed genetic and pharmacological experiments to uncover downstream and upstream mechanisms of serotonin signaling in fibrosis.

Downstream, there was evidence that serotonin signaling activates transforming growth factor- $\beta$ (TGFB; TGF $\beta$ ). Upstream, Distler thinks the serotonin originates from activated platelets that congregate at sites of ascular injury.

Indeed, blocking platelet activation with Plavix clopidogrel, an adenosine diphosphate purinergic receptor P2Y G protein-coupled 12 (ADP P2RY12) antagonist, prevented disease in a mouse model of chemically induced fibrosis. Plavix is marketed by Bristol-Myers Squibb Co. and Sanofi to treat acute coronary syndrome (ACS).

Also, mice lacking an enzyme needed for serotonin synthesis in the platelets proved resistant to fibrosis compared with wild-type controls.

Distler has filed patents on the modulation of serotonin signaling and said he is in the process of lar matrix proteins by fibroblasts. Previous studies have found signs of inflammation and autoimmunity around fibrotic lesions, but the precise roles of these processes, and how to modulate them, are unclear.

One player in the process is serotonin, which is best known as a neurotransmitter in the brain but also is produced outside of the brain by activated platelets. Platelet-derived serotonin is thought to act primarily as a vasoconstrictor, but recent observations have suggested serotonin can activate fibroblasts. ${ }^{2}$

Drawing on those observations, a team at the University of ErlangenNuremberg has connected the dots between platelet activation and pathogenic fibroblast activity. The researchers showed that serotonin is produced by activated platelets at vascular injury sites and identified the serotonin $\left(5-\mathrm{HT}_{2 \mathrm{~B}}\right)$ receptor as the target of the signaling molecule on the surface of fibroblasts.

\section{Serotonin blast}

The team found that serotonin induced higher expression of connective tissue genes in cultured fibroblasts and skin tissue biopsies from scleroderma patients than in those from healthy controls.

Next, the team examined levels of various serotonin receptors in scleroderma patient fibroblasts and found that levels of $5-\mathrm{HT}_{2 \mathrm{~B}}$, but not other serotonin receptors, were higher than levels in healthy control cells.

According to team leader Jörg Distler, professor of internal medicine at the university, "Serotonin mediates its profibrotic effects exclusively through this receptor." licensing the IP to an undisclosed company.

\section{Blue platelet special}

Distler's findings point to several possible processes or targets that could be hit to treat scleroderma, including platelet activation, serotonin biosynthesis, the $5-\mathrm{HT}_{2 \mathrm{~B}}$ receptor or the downstream TGF $\beta$ pathway. From a therapeutic standpoint, Distler thinks targeting $5-\mathrm{HT}_{2 \mathrm{~B}}$ is the best bet.

"It should be much more effective to target the receptor" than upstream components in the pathway, he said. "Targeting platelet activation could cause unwanted side effects," whereas hitting TGF $\beta$ with sufficient selectivity could be challenging.

Distler noted that "several compounds already in clinical use that target $5-\mathrm{HT}_{2 \mathrm{~B}}$ are known to be well tolerated."

He said his team, which included one researcher at Ergonex, is running a "small proof-of-concept Phase II trial" of terguride in scleroderma patients.

Last year, Ergonex granted Pfizer exclusive worldwide rights to terguride outside of Japan. The compound is marketed for hyperprolactinemia in Japan and is in Phase II testing for pulmonary arterial hypertension (PAH).

Ergonex CEO Rudolf Reiter told SciBX that Pfizer has ex-Japan rights to terguride for all indications. Pfizer spokesperson Victoria Davis said the pharma does not have a clinical development program in scleroderma but would not disclose whether it has plans for the compound in other fibrotic diseases. 
Distler also is testing whether the serotonin pathway he has worked out for scleroderma could be relevant to more common forms of fibrosis. "The upregulation of $5-\mathrm{HT}_{2 \mathrm{~B}}$ has not yet been found in other fibrotic diseases," he noted. "Our models are specific to the skin, but we are currently performing experiments in models of fibrosis of other organs-the lung and heart."

"To me, the most novel piece of this story is the platelet connection and the upregulation of TGF $\beta$ " caused by serotonin, said Shelia Violette, VP of research at Stromedix Inc. "The question is whether this process is a major driver of fibrosis or just a cofactor" that exacerbates disease already underway due to autoimmune or inflammatory processes.

She also wondered whether the dose of a $5-\mathrm{HT}_{2 \mathrm{~B}}$ antagonist like terguride needed for a therapeutic effect in scleroderma might be outside of the tolerable range for the molecules in other indications like PAH.

Besides terguride, other $5-\mathrm{HT}_{2 \mathrm{~B}}$ antagonists in the clinic are Biofrontera AG's BF-1, which has completed Phase 0 microdose testing for migraine, and Forest Laboratories Inc.'s PRX-8066, which is in Phase II trials for PAH associated with chronic obstructive pulmonary disease (COPD).

Stromedix's lead compound is STX-100, a mAb against integrin $\alpha_{v} \beta_{6}$ that is expected to enter a Phase IIa trial for idiopathic pulmonary fibrosis (IPF) this year.

Ray Jupp, VP of the Fibrosis and Wound Repair Therapeutic Strategy Unit at Sanofi, agreed that although serotonin has recently turned up as a suspect in other models of fibrosis, the involvement of platelets is a new angle.

"For me, the role of platelets in the fibrosis pathology is worth further consideration," said Jupp. "The major non-neuronal depot of serotonin is platelets."

However, serotonin may not be the only platelet-derived signaling molecule that contributes to fibrosis. Jupp cited evidence that activated platelets produce other profibrotic factors including lysophosphatidic acid (LPA), an inflammatory mediator. Blocking the receptor for Lpa ameliorated skin fibrosis in a mouse model. ${ }^{3}$
"The source of major LPA production is also the platelet, and [LPA] has also been shown to be in excess in the skin of scleroderma patients," said Jupp.

Sanofi's SAR156597, a bispecific antibody against IL-4 and IL-13, entered Phase I testing for IPF last quarter.

Peppi Prasit, CSO and cofounder of Amira, wanted to know how the proposed role of platelet-derived serotonin relates to the LPA pathway.

Amira's AM152, an inhibitor of lysophosphatidic acid receptor 1 (LPAR1; EDG2; LPA1), is slated to start a Phase IIa trial in scleroderma with lung involvement this year. The compound also has Orphan Drug designation to treat IPF.

Fibrosis is likely to be driven by various pathways acting in different proportions in different tissues, Prasit noted, so "there's not going to be a magic bullet" that is effective against all forms of the disease. However, he added that AM152 proved especially effective in preclinical models of scleroderma, suggesting that platelet-driven inflammatory processes are critical for this form of fibrosis. "It would be interesting to see whether inhibiting LPA could be combined with modulating serotonin signaling," said Prasit.

Osherovich, L. SciBX 4(19); doi:10.1038/scibx.2011.531

Published online May 12, 2011

REFERENCES

1. Dees, C. et al. J. Exp. Med.; published online April 25, 2011; doi:10.1084/ jem.20101629

Contact: Jörg H.W. Distler, University of Erlangen-Nuremberg,

Erlangen, Germany e-mail: joerg.distler@uk-erlangen.de

2. Fabre, A. et al. Eur. Respir. J. 32, 426-436 (2008)

3. Castelino, F.V. et al. Arthritis Rheum. 63, 1405-1415 (2011)

COMPANIES AND INSTITUTIONS MENTIONED

Amira Pharmaceuticals Inc., San Diego, Calif.

Biofrontera AG (Xetra:B8F), Leverkusen, Germany

Bristol-Myers Squibb Co. (NYSE:BMY), New York, N.Y.

Ergonex Pharma GmbH, Appenzell, Switzerland

Forest Laboratories Inc. (NYSE:FRX), New York, N.Y.

Pfizer Inc. (NYSE:PFE), New York, N.Y.

Sanofi (Euronext:SAN; NYSE:SNY), Paris, France

Stromedix Inc., Cambridge, Mass.

University of Erlangen-Nuremberg, Erlangen, Germany 